\title{
The Study of The Agricultural Product Logistics in Shenyang Based on The Perspective of The Supply Chain
}

\author{
Wang Xiaobin \\ School of Economic and Management \\ Shengyang Aerospace University \\ Shengyang China \\ 442685235@qq.com
}

\author{
Liu Chang \\ School of Economic and Management \\ Shengyang Aerospace University \\ Shengyang China \\ 896835136@qq.com
}

\begin{abstract}
China is a large agricultural country, the logistics of agricultural products in the national economy play a decisive role in the development of China, the development of the logistics industry,Among many fresh agricultural products, as the fruit and vegetable production and consumption power of Chinese fruit and vegetable product market appeared the product is relatively superfluous questions," dish cheap is hurt farming" occurred from time to time, product structure hasten, circulation construction pace is slow, retail channel disorder not free, price to rise, both delayed the consumption of people, but also influence the realization of the value of products, to construct the science reasonable fruit and vegetable supply chain of agricultural products is the key to solve the problem.This paper briefly introduces the importance of research on agricultural product logistics, modern logistics of agricultural products in the culvert, meaning, characteristics, as well as the basic idea of supply chain, then analyzed our country agricultural product logistics development present situation and the existence question, draw lessons from other areas of advanced logistics operation mode case, finally, based on the theory of supply chain in Shenyang agricultural products logistics and puts forward the countermeasure of development.
\end{abstract}

Keywords-agricultural; logistics; suply chain; situation and tendency

\section{INTRODUCTION}

There is necessity and urgency for Shenyang agricultural products logistics research. Shenyang locates in one of China's major agricultural province. The situation of Shenyang agricultural products logistics needs to strengthen logistics system research urgently. On the one hand, Shenyang agricultural products logistics volume is large. Shenyang locates in China's major agricultural province since ancient times, and it is a major or important producing area of rice, vegetables, pigs, corn. On the other hand, Shenyang agricultural products logistics development is lagged, which has become the bottleneck of agricultural products circulation development. Currently, Shenyang agricultural products logistics mainly have the following problems, scattered agricultural products logistics main body, unreasonable agricultural products logistics channels and nodes layout and constitute, backward agricultural logistics technical facilities and management methods and unsound agricultural logistics functions. The series of problems leads to artificially high transaction costs, poor distribution channels, excessive loss of circulation, and difficult circulation and value-adding during the circulation of agricultural products, which will increase the cost of agricultural products circulation reducing the efficiency of agricultural products circulation. Therefore, there is necessity and urgency to strengthen building Shenyang agricultural products modern logistics research, which is also one of the important backgrounds of the topic.

Firstly, the paper analyzes the status of Shenyang agricultural products logistics, to be the base of optimizing Shenyang agricultural products logistics through learning the development status and problems; Secondly, through books, literature, and network data collection and collation, we investigate the status of Shenyang agricultural products logistics development, combined with domestic and international agricultural products logistics experience, and build logistics operation mode with local characteristics; Thirdly, through this study, we propose countermeasures for optimizing agricultural logistics for Shenyang agricultural logistics problems, so as to improve logistics efficiency and ensure logistics quality.

\section{A. Introduction of Agricultural Logistics}

Among the concepts involved in agricultural products supply chain logistics system, there are too much crossresistance, some of the concepts exist extensive disputes in the academic community, therefore, it is necessary to define the main concepts covered in this article individually. They include defining the basic concepts of logistics, agricultural products logistics, supply chain, supply chain of agricultural products, agricultural products logistics service system and so on.

\section{B. Definition of agricultiral logistics}

China Federation of Logistics and Purchasing defines agricultural products as: agricultural products logistics, that is agricultural marketing logistics, refers to the physical movement between supply-side and demand-side, caused by the sale of agricultural products. It includes the transport and storage for selling agricultural products, distribution processing activities to meet the consumption needs of agricultural products and so on in a (China Logistics Development Report). 
Agricultural products supply chain is a supply chain based on a specific range of agricultural products. It refers to the agricultural products manufacturer and supplier (including seeds, pesticides, fertilizers and other production materials suppliers), producers (agricultural producers), agricultural products processing enterprises, distributors (wholesalers and retailers) and a functional chain structure consisting of agricultural products consumers. If the supply before agricultural production is included, agricultural products supply chain can be divided into two categories: first is agricultural production supply chain, that is secondary supply chain from production material supplier to agricultural products producers; Second, sales supply chain, that is three-level supply chain consisting of agricultural products producers, agricultural products processing enterprises, distributors and consumers. And related with agricultural products logistics concept, agricultural products supply chain in this article refers to agricultural products sale supply chain.

\section{Analysis on Shenyang Agricultural Products Logistics from the View of Supply Chain}

In recent years, Shenyang agricultural products logistics develops fast and infrastructure and logistics technology has been greatly improved, with a certain scale market and logistics needs, but due to the weak foundation, unreasonable institutional arrangements and insufficient public investment of Shenyang agricultural products logistics, Shenyang agricultural products logistics still has the following problems in the development process:

1) Unsound agricultural products logistics system

Because Shenyang agricultural products logistics industry started relatively late, agricultural logistics organizations are inadequate, government agencies, industry organizations, agricultural manufacturers and others didn't understand agricultural products logistics system comprehensively, so they didn't fully grasp the operating law of agricultural logistics yet, plus local protectionism of individual regions, resulting in that Shenyang hasn't formed a smooth agricultural products logistics system until now.

2) Small, scattered and weak agricultural products logistics main body

Agricultural products logistics main body is the carrier of modern agricultural products logistics development, but also reflects the value of agricultural product logistics. In recent years, with the rapid development of Shenyang agricultural products logistics, there are a variety of agricultural products logistics main bodies emerging across the province, responsible for the logistics of agricultural products. Overall, agricultural products logistics companies are small, logistics facilities are backward, modern logistics technology is not applied sufficiently, which is still an important factor restricting the development of agricultural product logistics of Liaoning Province.

3) Obstructed agricultural products logistics channels

Shenyang agricultural logistics system is not sound, resulting in agricultural logistics channel not smooth. The main mode of existing agricultural products circulation is circulating in accordance with "producing area acquisitiondistribution in producing area-sales market retail consumer purchase" channels. In the entire circulation chain, the unprocessed primary agricultural products account for the majority, most of them are perishable, but the existing refreshment means of agricultural products cannot adapt to this circulation pattern, resulting in a considerable portion of agricultural products damaged due to the reasons like transportation technology, storage technology, transportation infrastructure conditions and product preservation techniques and so on.

4) Development lag of agricultural products coldchain logistics

Agricultural products cold-chain logistics refers to special supply chain systems that meat, poultry, fish, vegetables, fruits, eggs and other fresh agricultural products, after being harvested (or slaughtered, fishing), for all steps of product processing, storage, transportation, distribution, retail, etc. they are always controlled in suitable low temperature environment, and product's quality and quality safety is ensured in maximum, to reduce losses and prevent pollution. Development of agricultural products cold-chain logistics has become a necessary means to protect the quality, reduce nutrient loss and ensure safety of agricultural products. At present, Shenyang agricultural products cold chain logistics development is still in its infancy, large-scale, systematic cold chain logistics system has not been formed, the size of cold-chain transport is small. The enterprises engaged in cold-chain transport are facing a lot of market pressure, basically relying on prices competition to attract customers. Due to the limited demand for refrigerated vehicles, the enterprises engaged in third-party cold-chain logistics are difficult to grow bigger.

\section{MEASURES TO IMPROVE SHENYANG AGRICULTURAL PRODUCTS LOGISTICS DEVELOPMENT BASED ON SUPPLY CHAIN VIEW}

The measures to improve Shenyang agricultural products logistics development based on supply chain view should foucus on strengthening the organization degree of logistics main body, taking optimizing and improving logistics supply chain model as the direction, to achieve integrating circulation resources, innovate circulation mechanism, standardize the market order, increase farmers' income, establish urban and rural coordinated and efficient circulation system of agricultural products and o meet the interests of producers, consumers and government.

\section{A. Logistics main bodies organization}

Logistics bodies include: production base, farmer cooperatives, large-scale wholesalers or wholesale markets, agricultural products processing enterprises, professional distribution centers, large supermarket chains and so on. These powerful logistics main bodies play an important role in price decision, agricultural products combination and logistics services, using their powerful position to form a more stable channel relationships, which are taken as the cores to establish logistics channels of fresh agricultural products respectively.

accelerate upgrading and rebuilding of agricultural products wholesale markets, and play a pivotal role of the wholesale market

accelerate the construction of leading agricultural products production and processing enterprises 
Support link between farmaers and supermarkets, and accelerate the construction of agricultural supermarket chains

develop rural cooperative economic organizations, to improve the degree of organization on farmers' access to markets.

\section{B. Standardization of logistics object}

Agricultural products object standardization refers to the technical requirements and norms of quality, specifications and all aspects related to quality of agricultural products. It includes common agricultural products uality standards, green agricultural standards, organic agricultural standards, pollution-free agricultural products standard and agricultural products grading. The standardization of agricultural products is beneficial to the standardization of logistics, which will help speed up the formation of agricultural logistics system.

\section{Logistics group federalization and collaboration}

\section{1) Logistics group federalization}

Modern logistics emphasises supply chain management model, namely the integration of agricultural products production, supply, sales resources, accelerating the establishment of cooperation among farmers, agricultural industry associations, leading companies , wholesalers, retailers, and promote running fresh products supply chain. The main agricultural products logistics include agricultural production farmers, processing companies, brokers and retailers, and they must form strategic alliances to survive and gain profits. In agricultural products circulation process, a strategic alliance is established by the main bodies to realize agricultural products value maximized and reasonal benefit-sharing. This alliance relationship involves various aspects of agricultural production, distribution and sales. To build a strong alliance partnerships, integrate the entire supply chain, the powerful circulation main bodies' roles playing should be emphasized, to exert the roles of their circulation bodies in profits distribution, providing services, information communication, protocol circulation, partnership establishment, to create highly efficient circulation system. One possible strategy is to develop protocols circulation. The agricultural products distribution channel members that restricted by agreement can keep stable partnership, shared interests and risks between each other .

\section{2) Logistics group collaboration}

To improve the competitiveness of agricultural industrial chain, the key is to achieve collaborative commerce among agricultural industrial chain node enterprises. Collaborative commerce refers to coreenterprises-led, through the use of modern production technology, management technology, information technology and process control technology to achieve effective planning and control of the information flow, supply chain, logistics, capital flow, business flow and value stream in the wholenetwork chain, thus connecting customers, R\&D centers, suppliers, manufacturers, distributors and service providers and other partners together into a complete chain structure, to meet the growing customers' demand and the ability of the enterprise through information sharing and concerted instruction in the whole interaction process. Through enhancing and integrating competitive advantages of the entire supply chain system to create and maximize business value and increase profitability.

\section{Logistics network informationization}

The basic requirements of agricultural products logistics supply chain management that based on core enterprises leading is to create a powerful, advanced, highly intelligent information technology platform on the premise that having necessary conditions. The basic functions of this IT platform are multi-protocol information intervention, intelligent information classification and identification, conducting e-commerce, realization of enterprises information exchange within the industry, enterprise and product promotion with network and network resource agreement sharing. To make this IT platform to function effectively, the support of supply chain node enterprises and government is needed. Electronic information processing center should be established between agricultural products farmers and cooperatives. The farmers can get market information through agricultural cooperatives to strengthen connection with agricultural markets; as a decentralized market information node, agricultural cooperatives can provide accurate market information for the farmers; leading processing enterprises can take advantage of information channels to learn the market demand and agricultural production conditions, based on which develop appropriate production and marketing strategies; in addition to using information serving their business, logistics information center also use the information to provide guidance for relevant enterprises and institutions of their production and sales; the relationship between the agricultural products vendors, supermarket chains and customers is the closest, that they can grasp the dynamics of market, and feed related information back to the logistics centers and enterprises, then to the cooperatives and farmers

\section{CONCLUSION}

China is a big agricultural country. With the improvement of agricultural productivity, the demand exceeding supply situation of agricultural products has become history, and agricultural products circulation problem becomes one challenge faced by the agriculture This paper drew and analyzed the study at home and abroad, connecting China's national conditions closely, and conducted deep and systematic research and made some research achievements on the theoretical basis of modern agricultural logistics development, evolution and current situation, development model, system construction and development countermeasures of Chinese agricultura products logistics. At this stage, agricultural products logistics in China has achieved initial development, but there is still much work to do. Learn from the successful experience of foreign agricultural products logistics development.

The research suggests that to develop modern agricultural products logistics, one side strength alone is not enough, the goals and interests of each major participant must be integrated and advance simultaneously from all levels. Therefore, Chinese modern agricultural 
logistics development mode selection proposed and system construction proposed in this paper has yet to accept practice tests; Meanwhile, agricultural logistics research and rational planning of system construction need further refinement.

\section{REFERENCES}

[1] u Gang. On resources transformation and operation of logistics enterprises demand [J]. Modern finance and economics, 2008,(10)

[2] Wang Xinlan. Existing problems and development countermeasures of China's agricultural logistics $[\mathrm{J}]$ Logistics technology, 2007 (9)

[3] Zhang Qian. Foreign agricultural logistics status $[\mathrm{J}]$. World agriculture 2007
[4] Ruan Chengjian, Wang Lili, Sun Hongling. Fruits and vegetables supply chain construction research [C]//China logistics academic frontier report (2007-2008) . Beijing: China material press, 2007

[5] Zhang Jingwei, Zhang Zhaotong. Developed countries agricultural products logistics development analysis and enlightenment $[\mathrm{J}]$ Agricultural economy, 2007

[6] Song Juanjuan. Agricultural products logistics property and related issues research: Southwest University, 2008

[7] Liu Qin. China's agricultural products logistics development and countermeasures research, Taiyuan: Shanxi University of Finance and Economics, 2007

[8] Zhang Ping, Wang Jian. Successful experience and enlightenment of foreign agricultural logistics development

[9] Wang Zhongjun, Introduction of foreign agricultural products logistics [J].World agriculture, 2007 